\title{
Maternidad subrogada: lagunas en el ordenamiento jurídico colombiano. ¿Con qué elementos cuenta el juez para adoptar su decisión?**
}

\author{
Carlos Andrés Romero Rubio
}

Recibido: 6 de mayo de 2018 • Aprobado: 15 de agosto de 2018

\section{Resumen}

Algunas mujeres, o más bien algunas parejas, motivadas por el hecho de no poder concebir un hijo y gracias a los avances de la ciencia y la tecnología, encontraron en métodos alternos tales como la inseminación artificial, la fecundación in vitro y la maternidad subrogada, una alternativa para conseguir tal fin. En países como India, Canadá y Portugal, entre otros, la maternidad subrogada o mal llamada "alquiler de vientre" se encuentra regulada. Dicha práctica en el ordenamiento jurídico colombiano no está prohibida, pero a la vez, tampoco se encuentra regulada. En el presente escrito se aborda el tema de la maternidad subrogada, sus implicaciones éticas, morales y jurídicas y se realizará una descripción de las lagunas jurídicas. El propósito de este artículo, es pues, analizar los vacíos jurídicos en el sistema jurídico colombiano en lo concerniente a la gestación subrogada y por último se describirán los elementos con los que cuenta el juez para tomar una decisión en este tema.

Palabras clave: maternidad subrogada, lagunas del derecho, iuspositivismo, ordenamiento jurídico, discrecionalidad judicial, principios.

* El presente artículo es producto de la investigación: "Maternidad subrogada: lagunas en el ordenamiento jurídico colombiano”, gestionado en el marco de la Facultad de Derecho de la Universidad Católica de Colombia y producto de la cátedra Teoría del Derecho, bajo la dirección de la profesora Estefanía Acosta Páez. Citar como: Romero Rubio, C. A. (2019). Maternidad subrogada: lagunas en el ordenamiento jurídico colombiano. ¿Con qué elementos cuenta el juez para adoptar su decisión? Revista IUSTA, 1(50), 177-191. DOI: https://doi.org/10.15332/1900-0448.2019.0050.07

** Estudiante del Programa de Derecho de la Universidad Católica de Colombia. Correo electrónico: caromero504@ucatolica.edu.co. ORCID: 0000-0002-6584-9705 


\title{
Surrogate motherhood: gaps in the Colombian LEGAL SYSTEM. WITH WHAT ELEMENTS DOES THE JUDGE HAVE TO MAKE HIS DECISION?
}

\begin{abstract}
Some women, or rather some couples, motivated by the fact of not being able to conceive a child, and thanks to advances in science and technology, found alternative methods such as artificial insemination, in vitro fertilization and surrogate motherhood, a alternative to achieve such an end. In countries like India, Canada and Portugal, among others, surrogacy or misnamed "belly rent", is regulated. This practice in the Colombian legal system is not prohibited, but at the same time it is not regulated either. In this paper, the subject of surrogate motherhood is addressed; its ethical, moral and legal implications, a description of the legal gaps will be made. The purpose of this article, then, is to analyze the legal gaps in the Colombian legal system regarding surrogate pregnancy and finally describe the elements that the judge has to make a decision on this issue.
\end{abstract}

Keywords: surrogate motherhood, legal gaps, iuspositivism, legal system, judicial discretion, principles.

\section{Maternidade SUbStituta: Lacunas no Sistema LEGAl COLOMBIANO. CoM QUE ElEMENTOS O JUIZ TEM QUE TOMAR SUA DECISÃO?}

\section{Resumo}

Algumas mulheres, ou melhor, alguns casais, motivadas pela incapacidade de conceber um filho, graças aos avanços da ciência e da tecnologia, encontrados em métodos alternativos, como a inseminação artificial, a fertilização in vitro e barriga de aluguel, um alternativa para atingir esse fim. Em países como Índia, Canadá e Portugal, entre outros, sub-rogação ou misnamed “aluguel de barriga”, é regulamentado. Essa prática no sistema legal colombiano não é proibida, mas ao mesmo tempo não é regulamentada também. Neste artigo, o tema da maternidade substituta é abordado; suas implicações éticas, morais e legais, será feita uma descrição das lacunas legais. O objetivo deste artigo, então, é analisar as lacunas legais no sistema legal 
colombiano em relação à gravidez substituta e, finalmente, descrever os elementos que o juiz tem para tomar uma decisão sobre essa questão.

Palavras-chave: maternidade substituta, lacunas na lei, iuspositivismo, ordem jurídica, discrição judicial, princípios.

\section{Introducción}

Siempre que se hace referencia a los sujetos de derechos normalmente se asimila esto con el concepto de persona, entendiendo a esta como la única concepción que existe dentro de la categoría de sujetos de derechos sin que se incluyan otras concepciones tales como la de sujeto de relevancia jurídica, sujeto de especial protección, etc. (Herrera, 2018).

De conformidad con Sánchez (2018),

[...] la tensión entre neoliberalismo y derechos humanos en América Latina ha servido como caldo de cultivos de nuevas categorías de análisis como el concepto de Estado constitucional regulador, que surge en un contexto de desarrollo económico volcado en la producción de materias primas y la consolidación constitucional de un discurso de los derechos (p. 95).

La maternidad es un fenómeno sociocultural complejo que trasciende los aspectos biológicos de la gestación y del parto, pues tiene además componentes psicológicos, sociales, culturales y afectivos del ser madre que se construyen en la interacción de las mujeres con otras personas en escenarios particulares, donde se viven universos simbólicos con significados propios (Cáceres-Manrique, Molina-Marín y Ruiz-Rodríguez, 2014, p. 319). Molina (2006) afirma: "La maternidad es un término que se encuentra en permanente evolución y en el cual inciden tanto factores culturales como sociales, los cuales lo han relacionado con las definiciones de mujer, procreación y crianza" (p. 93). Ahora bien, es de mencionar que la maternidad puede darse por mecanismos naturales, aunque hoy en día es común encontrar parejas que no pueden concebir hijos; por ejemplo, por problemas de fertilidad o parejas homosexuales que quieren tener hijos. Ante tal situación y gracias a los avances tecnológicos y científicos, entre estos la biotecnología, existen alternativas de procreación y maternidad. Dentro de 
estos métodos podemos encontrar la inseminación artificial, la fecundación in vitro, la transferencia de gametos y la maternidad subrogada, entre otros. Las anteriores alternativas de reproducción son llamadas técnicas de reproducción asistida. Según Monroy (2013), el concepto anterior se define como: "sistema de pasos y procedimientos biológicos apoyados, desarrollados y aplicados de manera médico-científica, que propenden por la sustitución u optimización del proceso biológico natural de la concepción humana” (p. 138). De todas las técnicas de reproducción asistida, la que interesa para el desarrollo de este escrito es la maternidad subrogada. Ahora, es preciso indicar qué se entiende por tal concepto. La maternidad subrogada se caracteriza porque "una mujer acepta la obligación de ser la gestante mediante cualesquiera de las técnicas reproductivas científicas y dar a luz al hijo de otras personas, entregando el niño al momento de su nacimiento o dentro de un término prudencial" (Pinzón, Rueda y Mejía, 2015, p. 86). En una primera instancia esta es la definición que se manejará; en el desarrollo del texto veremos otras aproximaciones que se han argumentado respecto a este concepto.

Surgen entonces algunas inquietudes que justifican y motivan este estudio: ¿existe actualmente regulación respecto a la maternidad subrogada?, ¿es legal esta práctica?, ¿qué implicaciones éticas y morales trae consigo esta práctica?, ¿con estas técnicas de reproducción surgen nuevos derechos y deberes para las partes involucradas? En el ordenamiento jurídico internacional y más exactamente en países como India, Canadá y Brasil, esta práctica cuenta con directrices bien claras e iniciativas legislativas que regulan el ejercicio de dicha actividad.

En el ordenamiento jurídico colombiano al parecer existen lagunas o vacíos jurídicos en esta materia. Por lo tanto, surge aquí un problema jurídico, objeto de este estudio, el cual reside fundamentalmente en determinar si: ¿existen lagunas en el sistema jurídico colombiano respecto a la maternidad subrogada? y de ser así, ¿con qué elementos cuenta el juez para tomar su decisión? Para dar solución a este interrogante se desarrollará en dos grandes apartados la temática de este artículo. La primera parte contiene la definición, características, implicaciones éticas y jurídicas de la maternidad subrogada y su regulación en el ordenamiento jurídico colombiano, así como los argumentos de los diferentes autores sobre el tema de las lagunas, escritores que con sus argumentos nos ayudarán a determinar si existen lagunas jurídicas en nuestro país en lo concerniente a este tema. En la segunda parte, se describirán los elementos con los que cuenta un juez para fundamentar 
su decisión en estos casos. Se analizará la discrecionalidad judicial planteada por Hart, Dworkin y la teoría de Ferrajoli.

En concordancia con lo dispuesto en líneas anteriores, es importante resaltar los cambios en las normas jurídicas y la importancia que se le da al proceso judicial para efectos de la eficacia, celeridad, protección y conservación de las garantías al debido proceso (Herrera, 2017).

\section{Primera parte}

\section{Lagunas jurídicas: su significado y su negación en el iuspositivismo}

Segura Ortega (1989) afirma:

Una laguna es la ausencia de regulación por parte del derecho (podría decirse mejor del ordenamiento jurídico para evitar mayores complicaciones) de una situación o caso determinado que requiere imperiosamente una respuesta concreta que no se halla especificada o explicitada en dicho ordenamiento jurídico y que es necesario buscar en el proceso de aplicación a través de la actividad integradora del juez (p. 289).

A lo largo de la historia algunos autores positivistas negaron la existencia de lagunas jurídicas. Se conocen dos teorías: la teoría del espacio jurídico vacío y la teoría de la norma general exclusiva. La primera de estas teorías tiene en Karl Bergbohm a su más importante exponente. Según este autor, "un derecho es siempre una totalidad existente sin lagunas. No necesita nunca ser llenado desde afuera, pues siempre está lleno, porque su entera fecundidad, su fuerza de expansión lógica dentro de su propio campo, cubre en todo momento la necesidad de los juicios jurídicos" (Segura Ortega, 1989, p. 290). Ni más ni menos, lo que con esta teoría se defiende es que no hay lagunas, porque el derecho es completo. Bobbio (1972, citado por Ramos), afirmó: "si el derecho era un sistema cerrado de normas no podía tener lagunas, porque si las tuviera sería difícil demostrar su independencia frente a aquellos otros ordenes normativos, como la moral, a los que sería casi inevitable acudir para rellenarlas" (p. 51).

La segunda teoría fue defendida por Zitelmann, Donati y Kelsen. Según esta doctrina "todas las normas jurídicas particulares que regulan determinadas conductas 
van acompañadas de una norma general-que normalmente solo se halla implícitacuya misión consiste en excluir todos aquellos comportamientos que no aparecen mencionados por la norma particular" (Segura Ortega, 1989, p. 293).

La doctrina kelseniana negaba la existencia de lagunas argumentando con la conocida tesis de que "lo que no está jurídicamente prohibido, está jurídicamente permitido" (Kelsen, 1935, p. 254).

\section{Las diferentes manifestaciones de las lagunas jurídicas}

Así como algunos iuspositivistas negaron la existencia de lagunas, otros defienden su existencia. Tal es el caso de Alchourrón y Bulygin. Ramos (2017), citando a estos dos autores, menciona que "si las soluciones previstas por las normas de un sistema jurídico no alcanzan a resolver todos los casos, diremos que ese sistema jurídico tiene lagunas". O, en palabras de Alchourrón y Bulygin, "cuando un caso genérico no encuentra solución en las normas de un sistema jurídico se dirá que ese caso es una laguna” (p. 57).

Para dichos tratadistas hay 4 tipos de lagunas (Ramos, 2017, pp. 58-60):

- Lagunas normativas: se presentan cuando un caso relevante jurídicamente no encuentra solución en las normas de un sistema jurídico. Son auténticas carencias de regulación del sistema jurídico y se consideran verdaderas lagunas del derecho. En este tipo de lagunas el sistema jurídico no ofrece solución para determinados casos.

- Lagunas de conocimiento: se presentan cuando no es posible determinar si un caso individual pertenece o no a un caso genérico, porque no se conocen bien las propiedades del hecho.

- Lagunas de reconocimiento: se presentan cuando en casos individuales en los cuales, por falta de precisión semántica de los conceptos que caracterizan a un caso genérico, no se sabe si pertenecen o no al caso genérico en cuestión.

- Lagunas axiológicas: aquellas en las cuales las normas no solucionan casos o propiedades que deberían considerarse relevantes con arreglo a alguna hipótesis de relevancia referida al sistema jurídico de que se trate. En este tipo de lagunas el sistema jurídico sí ofrece solución, pero es una solución insatisfactoria para el intérprete, porque este cree que debería considerarse relevante algún caso o propiedad al que el legislador no atribuye la relevancia que merece. 


\section{Contenido de la maternidad subrogada: significado según la doctrina y jurisprudencia. Características del contrato}

Tello (2009, citada por Monroy, 2013) define la maternidad subrogada como

[...] el compromiso entre una mujer, llamada "mujer gestante", a través del cual esta acepta someterse a técnicas de reproducción asistida para llevar a cabo la gestación en favor de una persona o pareja comitente, llamados el o los "subrogantes", a quien o a quienes se compromete a entregar el niño o niños que pudieran nacer, sin que se produzca vínculo de filiación alguno con la mujer gestante, sino con el o los subrogantes (p. 141).

La Corte Constitucional mediante la Sentencia T-968 de 2009 define la maternidad subrogada como el acto reproductor que genera el nacimiento de un niño gestado por una mujer sujeta a un pacto o compromiso mediante el cual debe ceder todos los derechos sobre el recién nacido a favor de otra mujer que figurará como madre de este.

León y Millán (2013) mencionan que el contrato de maternidad subrogada es de carácter bilateral, al existir obligaciones en cabeza de ambas partes; aleatorio, por ser incierto si la subrogada dará a luz un hijo; de ejecución instantánea, puesto que con la ejecución de la obligación se termina el contrato; consensual o solemne, dependiendo si en el país en que se ha permitido el contrato se exige algún tipo de solemnidad; y oneroso o gratuito, dependiendo lo acordado por las partes y lo permitido por la legislación (p. 8).

\section{Implicaciones éticas y jurídicas}

Camacho (2009, citado por López y Aparisi, 2012) afirma que:

La maternidad sustituta es una práctica basada en la decisión libre de adultos que ejercen sus derechos y prerrogativas, sin perjudicarse ni perjudicar a terceros. Todos los participantes y personas involucradas se suelen beneficiar de la misma: el niño que nace de dicho acuerdo no hubiera nacido si la práctica no se hubiera realizado y encuentra una familia que lo recibe con mucho amor y que lo deseó profundamente, los padres logran acceder a la paternidad y tienen la posibilidad de dar amor y brindarle todos los cuidados necesarios a su hijo y por último la mujer portadora 
puede satisfacer sus deseos de ayudar a otras personas y obtener un beneficio, en general económico a cambio de esa ayuda (p. 258).

Entre tanto, López y Aparisi (2012) mencionan que la realidad demuestra las profundas implicaciones éticas y jurídicas así como los numerosos problemas, de toda índole, que genera la práctica de la maternidad subrogada. Con respecto a la madre portadora, conlleva un serio riesgo de instrumentalización de su cuerpo ignorando la distinción básica entre personas y cosas a efectos de la celebración de un contrato. Afirma que la maternidad subrogada trae consigo implicaciones físicas y psíquicas, racionales y emocionales. Las madres portadoras sufren por tener que entregar obligatoriamente a los niños que han llevado en su seno (pp. $258,259,266)$.

Marín (2002) afirma que la maternidad subrogada es un atentado a la dignidad de la mujer, ya que en la subrogación el cuerpo femenino queda sometido a comercio. La mujer explota su útero con fines de lucro y lo emplea como incubadora de un niño que no va a ser suyo. Para este autor, ni "la mujer es una incubadora humana, ni el niño una mercancía” (p. 82).

Con respecto al hijo, la legalización de la maternidad subrogada supone mercantilizar la filiación ya que esta dependerá de la celebración de un contrato con un fuerte contenido económico. Por otro lado, la experiencia ha demostrado que el niño queda en una posición muy vulnerable dado que su situación depende de las cláusulas establecidas en dicho contrato, lo cual no asegura, en absoluto, la protección de sus intereses y derechos, por ejemplo, que pueda ejercer el derecho a conocer a su madre uterina (López y Aparisi, 2012, p. 266).

Por último, coinciden con otros autores en que el contrato de subrogación se asemeja peligrosamente a un contrato de compraventa de niños (p. 261).

\section{La maternidad subrogada en el ordenamiento jurídico colombiano: análisis legislativo y jurisprudencial}

En Colombia es evidente la ausencia de una ley expresa que regule la maternidad subrogada. Russi (2010) afirma que,

[...] si bien no existe una regulación específica en la materia, tampoco existe norma que la prohíba; por el contrario, con fundamento en el artículo 42 de nuestra 
Constitución Política, el cual otorga los mismos derechos de los hijos naturales a aquellos que hayan sido procreados con asistencia científica, podría decirse que el arrendamiento de vientre está permitido (pp. 24-25).

El Decreto 1546 de 1998, en su artículo segundo, define las unidades de biomedicina reproductiva como todas aquellas que prestan servicios de estudio, asistencia, tratamiento e investigación en salud reproductiva con especial énfasis en la infertilidad de la pareja, incluyendo actos quirúrgicos de diagnóstico y tratamiento con técnicas de reproducción asistida que contemplan la obtención de preembriones, que vayan en beneficio de la recuperación de la fertilidad tanto de la mujer como del varón, la obtención de material biológico con el mismo fin y la posibilidad del logro de un embarazo.

Como se ha mencionado anteriormente, la práctica de la maternidad subrogada en nuestro país carece de una ley clara y específica en esta materia. Ante la necesidad de legislación, se han presentado varios proyectos de ley los cuales han sido archivados. Actualmente, cursa en el Congreso de la República el proyecto de ley 202 del 2016, el cual tiene por objeto prohibir la práctica de la maternidad subrogada en Colombia, con el fin de proteger los derechos a la dignidad, intimidad, igualdad, autonomía, procreación y salud de la mujer, así como el derecho a la vida y al de conformar una familia de quien está por nacer. El fundamento de su prohibición se basa en que esta práctica se considera como una categoría de trata de personas y explotación de la mujer con fines reproductivos.

Jurisprudencialmente, el único precedente es la Sentencia T-968 de 2009. La Corte Constitucional resolvió recurso de revisión de tutela en el cual dentro de sus consideraciones más relevantes, definió el contrato de maternidad, manifestó la importancia de regular legislativamente esta modalidad y dispuso que con observancia del texto constitucional, este negocio jurídico gozaba de validez ( Russi, 2010, p. 25). 


\section{Segunda parte}

\section{Elementos con los que cuenta el juez para decidir en ausencia de legislación}

\section{La discrecionalidad judicial en Hart y Dworkin}

Iglesias (citado por Etcheverry, 2015, p. 1398) argumenta que la discrecionalidad judicial hace referencia a "una serie de cuestiones diferentes y relacionadas: por un lado, a la prudencia, sensatez o buen juicio que debe acompañar a una decisión y, por el otro, al arbitrio o la voluntad admisibles en ella”. Uno de los grandes iuspositivistas del siglo pasado, Herbert Hart, dedicó varias páginas en su obra cumbre, The concept law, al tema de la discrecionalidad judicial. Ramos (2017) cita a Hart afirmando que dicho autor arguye que,

[...] los jueces tienen un cierto margen de discrecionalidad para resolver, frente a las circunstancias de cada caso, las indeterminaciones de las normas jurídicas. Esa discrecionalidad no equivale a arbitrariedad sino a buen juicio e implica que los jueces deben apoyar sus decisiones en pautas razonables, que bien podrían ser principios morales, aunque no formen parte del derecho (p. 55).

Etcheverry (2015) trae a colación una tesis de Hart donde se describe que,

$[\ldots]$ se prefiere reconocer que algunos casos no tienen una respuesta jurídica completamente determinada y otorgar a los jueces facultades discrecionales orientadas por principios, para que puedan decidir teniendo en cuenta las circunstancias particulares, en lugar de aplicar forzadamente un derecho a casos que no fueron previstos (p. 1394).

A la vez, menciona que,

[...] el juez debe ejercer su poder de creación de derecho, pero no debe hacerlo arbitrariamente: es decir, debe siempre tener algunas razones generales que justifiquen su decisión y debe actuar como lo haría un legislador concienzudo, decidiendo de acuerdo a sus propias creencias y valores (p. 1400). 
Dentro de esos principios mencionados bien se puede hacer alusión al principio de justicia. Hart (1961) menciona que el principio general en la idea de justicia es que los individuos tienen derecho a una cierta posición relativa de igualdad o desigualdad. La justicia se concibe como el mantenimiento o restablecimiento de un equilibrio o proporción en donde su precepto principal se formularía de la siguiente manera: "tratar los casos semejantes de la misma manera" y "tratar los casos diferentes de diferente manera “(p. 198). Arguye a la vez, de que prima facie los seres humanos deben ser tratados con igualdad.

Entre tanto, Ronald Dworkin en su libro Los derechos en serio (1977), realiza una crítica al positivismo y en especial a Hart. En lo referente a la discreción judicial, Dworkin hace su crítica al iuspositivismo afirmando que estos aluden que, ante la ausencia de una regla, el juez decide teniendo en cuenta criterios subjetivos, argumentando lo siguiente:

El conjunto de estas normas jurídicas válidas agota el concepto de derecho, de modo que si alguna de tales normas no cubre claramente el caso de alguien (porque no hay ninguna que parezca apropiada, o porque las que parecen apropiadas son vagas o por alguna otra razón), entonces el caso no se puede decidir aplicando la ley. Ha de ser decidido por algún funcionario, por ejemplo un juez, que ejerza su discreción, lo que significa ir más allá de la ley en busca de algún otro tipo de estándar que lo guíe en la preparación de una norma nueva o en la ampliación de una existente (p. 65).

Para dicho autor, el significado de la palabra discreción se afecta por el contexto en que se use. Se puede hablar de discreción en sentido débil (cuando la aplicación de una norma requiere discernimiento), en un sentido débil diferente (cuando la decisión tomada por un funcionario no puede ser anulada o revisada por otro) y en sentido más fuerte (para aludir su alcance y las decisiones que pretende controlar). Ahora bien, es preciso mencionar que para Dworkin

[...] la discreción de un funcionario no significa que sea libre para decidir sin que tenga que recurrir a normas de sensatez y justicia, sino solamente que su decisión no está controlada por una norma prevista por la autoridad particular en que pensamos al plantear la cuestión de la discreción (pp. 84-86). 
Por tanto, teniendo en cuenta la tesis expuesta anteriormente y acorde al concepto de derecho manejado por Dworkin, cuando en un ordenamiento jurídico existen principios, el juez ante casos difíciles puede acudir a ellos para fundar su decisión. El juez en estos casos está facultado y a la vez obligado para aplicar los principios, pues estos hacen parte integral del derecho.

\section{Teoría de Luigi Ferrajoli}

Ferrajoli hace mención especial a la maternidad subrogada. Para dicho autor, en esta práctica "la gestación de un niño se lleva adelante por una mujer diversa de aquella a la que pertenece el óvulo fecundado, en virtud de un acuerdo previamente adoptado". A la vez, plantea que el principio de autodeterminación de la mujer a decidir sobre su propio cuerpo, en donde decide voluntariamente acceder a la maternidad, es el que prima en este tipo de procedimientos. Para Ferrajoli, la gestación o maternidad subrogada solo se admite bajo la forma de donación (Ferrajoli, 2002, pp. 269-270). Finalmente, argumenta que solamente cuando haya conflicto o cuando se afecten derechos fundamentales debe intervenir el derecho. Para el jurista italiano, bastaría con una simple ley de garantía, dirigida a asegurar la ausencia de discriminación, la dignidad y los derechos fundamentales de todas las personas implicadas. Incluso, menciona que sería preferible ausencia de legislación, donde la solución del problema jurídico se confíe a la autonomía, responsabilidad individual e intervención equitativa del juez. Por último, defiende una tesis donde argumenta que una regla general y abstracta en estos casos sería inoportuna, para él es más viable una decisión judicial precedida de intentos de mediación y composición del conflicto (pp. 274-275).

\section{Conclusiones}

1. La maternidad subrogada es una técnica de reproducción asistida, la cual no está prohibida en el ordenamiento jurídico colombiano. Carece de una regulación específica y expresa. Hace falta una ley clara y específica que regule esta práctica en nuestro país. Colombia, como Estado social de derecho, debe implementar una legislación concreta respecto a este tema, que garantice seguridad jurídica a las partes involucradas. 
2. En casos de lagunas o ausencia de legislación en un tema específico, como es el caso que nos ocupa, el juez tiene potestad legislativa, autonomía y discrecionalidad para tomar una decisión. No debe confundirse con arbitrariedad ya que debe tener argumentos que justifiquen su decisión y no ir en contra de la ley.

3. Ante ausencia de legislación, el juez debe optar por los principios que hacen parte esencial del derecho y del ordenamiento jurídico para fundar su decisión. Estos principios orientan y determinan un fallo judicial. Por lo tanto, el juez puede acudir a los principios generales del derecho, a la justicia y equidad para adoptar su decisión.

4. En casos de maternidad subrogada el derecho debe salvaguardar los derechos fundamentales. Para las madres proteger el derecho a la igualdad, libre desarrollo de la personalidad y dignidad. Entre tanto, para el futuro hijo debe prevalecer el principio del interés superior del menor.

5. Se resalta el único antecedente emitido por la Corte Constitucional con respecto a este tema. Dicha corporación, en la Sentencia T-968 de 2009 definió algunas directrices para la práctica de la maternidad subrogada. Este fallo, sin lugar a dudas, sirve como referente para casos similares. Por lo tanto, esta sentencia actúa como precedente y tiene fuerza vinculante. El juez puede recurrir a razonamientos analógicos para colmar estas lagunas jurídicas.

\section{Referencias}

Cáceres-Manrique, F. M., Molina-Marín, G., y Ruiz-Rodríguez, M. (2014). Maternidad: un proceso con distintos matices y construcción de vínculos. Aquichan, 14(3), 316-326. DOI: 10.5294/aqui.2014.14.3.4. Recuperado de file://C:/Users/Usuario/Downloads/ Dialnet-Maternidad-4955949.pdf

Decreto 1546. (1998). Por el cual se reglamentan parcialmente las Leyes 9a de 1979, y 73 de 1988, en cuanto a la obtención, donación, preservación, almacenamiento, transporte, destino y disposición final de componentes anatómicos y los procedimientos para trasplante de los mismos en seres humanos, y se adoptan las condiciones mínimas para el funcionamiento de las Unidades de Biomedicina Reproductiva, Centros o similares. Presidencia de la República, Diario Oficial n.o 43.357 de la República de Colombia, Bogotá D. C., 4 de agosto de 1998. 
Dworkin, R. (1977). Los derechos en serio. Barcelona, España: editorial Ariel.

Etcheverry, J. (2015). Discrecionalidad judicial. Enciclopedia de Filosofía y Teoría del Derecho. 2, pp. 1389-1418. Recuperado de http://biblio.juridicas.unam.mx/libros/libro.htm?l=3796 Ferrajoli, L. (2012). La cuestión del embrión entre derecho y moral. Jueces para la democracia. Información y Debate, 44, 255-275. Recuperado de www.jurídicas.unam.mx.

Hart, H. (1961). El concepto de derecho. Buenos Aires, Argentina: editorial Abeledo-Perrot.

Herrera, J. (2017). La responsabilidad médica frente a la reforma del Código de Procedimiento Civil y del Código Contencioso Administrativo. Revista IUSTA, 1(46), 85-114. DOI: http://dx.doi.org/10.15332/s1900-0448.2017.0046.04. Recuperado de http:// revistas.usta.edu.co/index.php/iusta/article/view/3527/3417

Herrera, B. (2018). Derechos de los animales: la legislación nacional interna como barrera legal para el reconocimiento de la subjetividad jurídica animal. Revista Via Inveniendi et Iudicandi, 13(1), 55-93. DOI: http://dx.doi. org/10.15332/s1909-0528.2018.0001.02. Recuperado de http://revistas.usantotomas.edu.co/index.php/viei/article/view/4266/4043

Kelsen, H. (1935/2005). Teoría pura del derecho. México, D. F., México: Editorial Porrúa. León, K., y Millán, J. (2013). El futuro de la maternidad subrogada en Colombia: una perspectiva desde las experiencias de España y México (trabajo de grado). Universidad Javeriana, Bogotá D. C., Colombia. Recuperado de https://repository.javeriana.edu.co/ handle/10554/15354

López, J., y Aparisi, A. (2012). Aproximación a la problemática ética y jurídica de la maternidad subrogada. Cuadernos de Bioética, 23(2), 253-267. Recuperado de http://repositorio. gire.org.mx/bitstream/123456789/2684/1/87524464001.pdf

Marín, G. (2002). El arrendamiento de vientre en Colombia. Opinión Jurídica, 2(3), 6986. Recuperado de http://revistas.udem.edu.co/index.php/opinion/article/view/1336.

Molina, M. (2006). Transformaciones histórico-culturales del concepto de maternidad y sus repercusiones en la identidad de la mujer. Psykhe, 15(2), 93-103. Recuperado de https://scielo.conicyt.cl/scielo.php?script=sci_arttext\&pid=S0718-22282006000200009.

Monroy, J. P. (2013). Técnicas de reproducción asistida y su incidencia en Colombia. Revista Verba Iuris, 30, 135-150. Recuperado de http://www.unilibre.edu.co/verbaiuris/30/ tecnicas-de-reproduccion-asistida-y-su-incidencia-en-colomnia.pdf

Pinzón, I., Rueda, E., y Mejía, O. (2015). La aceptabilidad jurídica de la técnica de gestación de vida humana por sustitución de vientre. Revista de Derecho y Genoma Humano. Genética, Biotecnología y Medicina Avanzada, 43, 83-122. Recuperado de http://www. javeriana.edu.co/documents/4578040/4715782/RevDerechoyGenomaH_83-122/ dd919031-4548-4978-945a-d81b480f3cd9. 
Proyecto de ley 202. (2016). Por medio de la cual se prohíbe la práctica de la maternidad subrogada al ser una categoría de trata de personas y explotación de la mujer con fines reproductivos. Cámara de Representantes, Congreso de Colombia. Recuperado de http:// www.imprenta.gov.co/gacetap/gaceta.mostrar_documento?p_tipo $=0$

Ramos, J. A. (2017). Lagunas del derecho y positivismo jurídico. Un examen de la concepción de las lagunas de C. Alchourrón y E. Bulygin. Cuadernos de Filosofía del Derecho, 40, 49-68. DOI: 10.14198/DOXA2017.40.02

Russi, S. (2015). Régimen jurídico de la maternidad subrogada en Colombia: un estudio doctrinal y jurisprudencial sobre la validez del contrato y sus efectos para las partes. Bogotá D. C., Colombia: Editorial Universidad Católica. Recuperado de http://repository.ucatolica. edu.co/handle/10983/2695

Sánchez, R. (2018). La regulación de participación. El caso de la consulta previa en Colombia, Perú y Chile. Revista Via Inveniendi et Iudicandi, 14(1), 95-118. DOI: http://dx.doi. org/10.15332/s1909-0528.2018.0001.03. Recuperado de http://revistas.usantotomas. edu.co/index.php/viei/article/view/4267/4044

Segura Ortega, M. (1989). El problema de las lagunas en el derecho. Anuario de Filosofía del Derecho, 6, 285-312. Recuperado de https://dialnet.unirioja.es/descarga/articulo/1985307.pdf

Sentencia T-968. (18 de diciembre de 2009). Corte Constitucional de Colombia, Sala Segunda de Revisión. M. P. María Victoria Calle. 